\title{
Analysis on Precipitable Water Vapor over the Tibetan Plateau Using FengYun-3A Medium Resolution Spectral Imager Products
}

\author{
Shaoqi Gong $\mathbb{D},{ }^{1,2,3}$ Daniel F. T. Hagan, ${ }^{1}$ and Cunjie Zhang $\mathbb{D}^{2,4}$ \\ ${ }^{1}$ School of Remote Sensing and Geomatics Engineering, Nanjing University of Information Science \& Technology (NUIST), \\ Nanjing 210044, China \\ ${ }^{2}$ National Climate Center, China Meteorological Administration, Beijing 100081, China \\ ${ }^{3}$ NUIST-UoR International Research Institute, Nanjing 210044, China \\ ${ }^{4}$ Key laboratory for Cloud Physics of China Meteorological Administration, Beijing 100081, China \\ Correspondence should be addressed to Cunjie Zhang; 693246609@qq.com
}

Received 30 March 2019; Accepted 26 August 2019; Published 28 November 2019

Guest Editor: Dongfeng He

Copyright (C) 2019 Shaoqi Gong et al. This is an open access article distributed under the Creative Commons Attribution License, which permits unrestricted use, distribution, and reproduction in any medium, provided the original work is properly cited.

\begin{abstract}
The Tibetan Plateau is the largest and highest plateau in the world, and its complex terrain affects the distribution of precipitable water vapor $(\mathrm{PWV})$ in the atmosphere, which plays an important role in the weather and climate of East Asia. In this paper, the characteristics of PWV over the Tibetan Plateau are studied using the FengYun-3A Medium Resolution Spectral Imager (MERSI) water vapor products, which are retrieved from the MERSI raw images of Chinese second-generation polar orbit meteorological satellite. Firstly, the accuracy of the MERSI 5-minute water vapor product is validated using three referenced water vapor data from TERRA/MODIS, ground-based GPS, and AERONET sun photometer over the Tibetan Plateau. Then, the spatial distribution and seasonal variation of PWV over the plateau are analyzed, and the effects of topographic factors on PWV are discussed. The results indicate that the MERSI 5-minute water vapor product has a good accuracy over the Tibetan Plateau, which the mean absolute error of MERSI water vapor product is in the range of $28.91 \%-37.54 \%$, the mean absolute error range between 1.87 and 2.76 millimeter $(\mathrm{mm})$, and the mean bias is between -1.14 and 0.64 mm comparing three referenced data. The PWV content appears as a typical spatial pattern over the Tibetan Plateau where there is a decrease from east to west of the Tibetan Plateau with increasing elevation, with the highest values over the south of Tibet. A second pattern also appears over the eastern part of the Tibetan Plateau, where the PWV content in the Qaidam Basin and the south of Tarim Basin are also considerably high. The seasonal variation of PWV content over the Tibetan Plateau presents to be highest in summer, followed by autumn and spring, and lowest in winter. The PWV content changes periodically during the year, which fits with a quadratic polynomial over monthly scales. The topographical factors of the Tibetan Plateau were found to affect the water vapor, where the altitude and latitude are negatively correlated with water vapor, while the slope and longitude show a positive correlation with water vapor; however, the aspect does not appear to have any significant influence on water vapor.
\end{abstract}

\section{Introduction}

The Tibetan Plateau is the highest and largest plateau in the world and is surrounded by the highest mountains on Earth. It is called the roof of the world, as well as the third pole of the earth [1]. The elevation in the most areas is $6000-7000 \mathrm{~m}$ and the average altitude is above $4000 \mathrm{~m}$. The distances are $2800 \mathrm{~km}$ in the east-west direction and $300-1500 \mathrm{~km}$ from north to south, with a total area of about 2.4 million $\mathrm{km}^{2}$, accounting for about $1 / 4$ of land area of China [2]. Large- scale complex terrain on the plateau can block, divert, and direct the atmospheric circulation. It also influences the solar radiation and the energy balance of the earth and atmosphere system [3]. Hence, the Tibetan Plateau plays an important role within the weather and climate of East Asia, and even globally [4]. Due to the thermodynamic forcing of the plateau, the precipitable water vapor (PWV) content over the Tibetan Plateau possesses significant temporal and spatial variability [5]. Since PWV is a key atmospheric constituent despite the low proportion in the atmosphere, it is a 
necessary factor to generate cloud and precipitation, and it can affect the local water circulation process, heat up the whole climate system, and produce global greenhouse effects [6]. The research on the water vapor over Tibetan Plateau is useful to understand the water cycle process in the surrounding areas, the ecological environmental changes, the drought and flood disasters, and several weather and climatic phenomena.

As for the PWV measurement methods, the groundbased GPS [7], Sun photometer [8], microwave radiometer [9], and radiosonde [10] can accurately measure the atmospheric water vapor. Since the number of observation station is limited, and its distribution is uneven, the instrument measurements on ground cannot be applied to properly study the of PWV spatial distribution characteristics. The NCEP/NCAR reanalysis data and NVAP dataset can provide global water vapor data [11], but the spatial resolution is too low. With the development of remote sensing technology, there has been some satellite remote sensing water vapor products with high temporal and spatial resolution, such as the water vapor product of TERRA/MODIS which was developed by Gao and Kaufman [12, 13] with the MODIS original images in the near-infrared channels, that of FY-3A/MERSI which was developed by the National Satellite Meteorological Center of China from raw data in the near-infrared channels of the Medium Spectral Resolution Imager (MERSI) onboard the FY-3A satellite. At present, more researchers have employed the use of MODIS water vapor products [13-16] while less make use of the MERSI water vapor products in the research. So this paper will firstly validate the MERSI water vapor products over the Tibetan Plateau, then analyze the temporal and spatial distribution characteristics of water vapor over the Plateau, and finally discuss the influence of the Plateau topography on water vapor.

\section{Data and Methods}

2.1. FY-3A/MERSI Water Vapor Products. FY-3A was the first spacecraft among the second generation of Chinese polar orbit meteorological series satellites, which was launched on May 27, 2008 with a $836 \mathrm{~km}$ altitude, near-sun synchronous orbit, and the passing time for 10:30 A.M at an equatorial descending node. The Medium Resolution Spectral Imager (MERSI) is a payload onboard FY-3A, containing 20 channels with the spectral coverage from visible, near-infrared to thermal infrared band, and MERSI has two nadir spatial resolutions with $250 \mathrm{~m}$ for channel 1-5 and $1000 \mathrm{~m}$ for channel 6-20, their spectral specifications can be seen in Reference [17]. MERSI can provide daily observations for the global scientific studies about the atmosphere, ocean, and land. The National Satellite Meteorological Center of China has developed the atmospheric PWV products using the MERSI raw data in the near-infrared channels, which include 5-minute, global daily, 10-day, and monthly water vapor products. And the MERSI daily, 10day and monthly water vapor products with global coverage and $5 \mathrm{~km}$ spatial resolution are aggregated by the 5 -minute one after some preprocessing procedures, such as the projection transformation and image mosaicking.

The retrieval principle of the MERSI water vapor product is the differential absorption method [18]. Because the strong absorption of water vapor occurs in the three near-infrared channels (centered at $0.905,0.940$, and $0.980 \mu \mathrm{m}$ ) and the weak absorption appears in their nearby atmospheric window channels (centered at 0.865 and $1.030 \mu \mathrm{m}$ ), the channel ratio from the absorption and window channel calculated by Equation (1) or (2) can reflect the absorption properties of water vapor.

$$
\begin{gathered}
\frac{\rho_{\mathrm{PWV}}^{*}}{\rho_{0}^{*}}=\left(\frac{\rho_{\mathrm{PWV}}}{\rho_{0}}\right) \rho_{0}, \\
\frac{\rho_{\mathrm{PWV}}^{*}}{\left(k_{01} \rho_{01}^{*}+k_{02} \rho_{02}^{*}\right)}=\left[\frac{\rho_{\mathrm{PWV}}}{\left(k_{01} \rho_{01}+k_{02} \rho_{02}\right)}\right] T_{\mathrm{PWV}},
\end{gathered}
$$

where $\rho^{*}$ and $\rho$ are the reflectance at the top of the atmosphere and surface, respectively; the subscript PWV and 0 are the absorption and window channels, respectively; 01 and 02 are the two adjacent window channels, while $k_{01}$ and $k_{02}$ are the scale factors between the absorption and window wavelength $\lambda$. It can be calculated by Equations (3) and (4):

$$
\begin{aligned}
& k_{01}=\frac{\left(\lambda_{\mathrm{PWV}}-\lambda_{01}\right)}{\left(\lambda_{02}-\lambda_{01}\right)}, \\
& k_{02}=\frac{\left(\lambda_{02}-\lambda_{\mathrm{PWV}}\right)}{\lambda_{02}-\lambda_{01}} .
\end{aligned}
$$

When the surface is covered by only one natural feature and the wavelengths of the absorption and window channels are very close, $\rho_{\mathrm{PWV}}$ is approximately equal to $\rho_{0}$; thus, Equation (1) can be rewritten as shown in Equation (5).

$$
\frac{\rho_{\mathrm{PWV}}^{*}}{\rho_{0}^{*}}=T_{\mathrm{PWV}} .
$$

Assuming that the surface reflectance varies linearly with wavelength, the reflectance in the absorption channel can be expressed by that in two window channels, that is $\rho_{\mathrm{PWV}}=k_{01} \rho_{01}+k_{02} \rho_{02}[2,13]$; hence, Equation (2) can be also be rewritten as shown in Equation (6).

$$
\frac{\rho_{\mathrm{PWV}}^{*}}{\left(k_{01} \rho_{01}^{*}+k_{02} \rho_{02}^{*}\right)}=T_{\mathrm{PWV}} \text {. }
$$

Therefore, the atmospheric water vapor transmittance in the three absorption channels can be derived by the channel ratio, respectively, and the water vapor content of each channel is extrapolated according to the lookup table of water vapor and transmittance. Since the sensitivity in the different absorption channels is distinct for the PWV content, the sensitivity $\eta$ is defined by taking the derivative of transmittance 
TABLE 1: Date of MERSI 5-minute water vapor product and three referenced water vapor data.

\begin{tabular}{lc}
\hline Season & Date \\
\hline Winter & January to February 2010; \\
& $\begin{array}{c}\text { December 1, 2010 to January 12, 2011; } \\
\text { December 2011; January 2012; } \\
\text { January 20 to February 28 2013 }\end{array}$ \\
\hline Spring & March and April 2012; \\
& April and May 2010; April 2013 \\
Summer & July 1 to August 10, 2012; \\
& June and July 2010; July 2013; \\
& June and August 2011 \\
\hline \multirow{3}{*}{ Autumn } & October 2 to November 30, 2009; \\
& October 2010 and 2013; \\
\hline
\end{tabular}

on PWV content, $\eta_{i}=\Delta \tau_{i} / \Delta \mathrm{PWV}_{i}$, here $i$ is the number of absorption channel. Finally, the PWV content is calculated from that of three absorbing channels by the sensitivity weighted mean, $\mathrm{PWV}=\sum f_{i} \mathrm{PWV}_{i}$, where $f_{i}$ is the weighting function of the $i^{\text {th }}$ absorption channel which is defined as $f_{i}=\eta_{i} /\left(\eta_{1}+\eta_{2}+\eta_{3}\right)$. In order to utilize MERSI water vapor products in this research, the accuracy of MERSI water vapor 5-minute product is validated, respectively, with three synchronous referenced water vapor data retrieved from the measurements of the ground-based GPS, AERONET Sun photometer [19], and Terra/MODIS. The validated data cover four seasons including spring, summer, autumn, and winter and their dates are summarized in Table 1 . Since the weather is not always sunny during these dates, the water vapor data from Sun photometer, MERSI, and MODIS are also not continuous. Furthermore, MERSI monthly water vapor products from February 2010 to September 2015 are applied to analyze the spatial and temporal variability of water vapor over the Tibetan Plateau. All the MERSI water vapor products are available in the FengYun satellite remote sensing data service network (http://satellite.cma.gov .cn/portalsite/default.aspx).

\subsection{The Referenced Water Vapor Data}

2.2.1. Water Vapor Data from the Ground-Based GPS. With the rapid development of the GPS meteorology since the 1980s, the PWV content retrieved from the measurements of the ground-based GPS has an accuracy with a rootmean-square of $1.0-2.1 \mathrm{~mm}$ in contrast with that from the microwave radiometer or radiosonde [20-23]. The atmospheric PWV content is able to be calculated accurately from GPS estimates of troposphere zenith path delay (ZPD) at the ground tracking stations. And the International GNSS Service (IGS) provides a long-term and continuous ZPD product for a 5-minute interval at the level of 4-6 $\mathrm{mm}$ corresponding to the PWV error less than $1 \mathrm{~mm}$ [24]. There is an available IGS station with elevation $3622 \mathrm{~m}$ in the Tibetan Plateau (Figure 1). Generally, the troposphere zenith path delay is sourced from two parts: a zenith hydrostatic delay (ZHD) and a zenith wet delay (ZWD). The ZHD can be expressed as a function of the geodetic height $H$, geodetic latitude $\varphi$, and atmospheric pressure $P_{\mathrm{s}}$ [25], and the ZWD can be calculated by subtracting ZHD from ZPD. Then, PWV is obtained by ZWD multiplying a constant of proportionality $\Pi$. The algorithm about PWV calculated from GPS measurements is cited by Lu et al. [26]. The ZPD and relative meteorological data are available on the website $\mathrm{ftp}: / /$ cddis.gsfc .nasa.gov/. And the dates of all GPS water vapor data are corresponding to those of MERSI water vapor 5-minute product and summarized in Table 1.

2.2.2. AERONET Water Vapor Data. The AERONET (Aerosol Robotic Network) project is established by NASA and PHOTONS (Photométrie pour le Traitement Opérationnel de Normalisation Satellitaire) for a federation of groundbased remote sensing aerosol networks [19], which provides a long-term, continuous, and readily accessible public domain dataset of aerosol and water vapor. The Sun photometer CE318 with 8 channels ranged from 340 to $1020 \mathrm{~nm}$ (made by the French company CIMEL Electronique) is the standard instrument in the AERONET and is applied to observe aerosol optical parameters and PWV content for a 15-minute interval. Since the level 2.0 data of AERONET has undergone cloud screening and quality control, the uncertainty of AERONET water vapor data is $12 \%$ [27]. In this study, the water vapor data from 16 AERONET stations in the Tibetan Plateau (Figure 1) are considered the reference to validate the MERSI 5-minute water vapor product. The level 2.0 data of AERONET are derived from the website (http://aeronet.gsfc.nasa.gov/). And the dates of all AERONET data are corresponding to those of MERSI 5-minute water vapor product and summarized in Table 1.

2.2.3. TERRA/MODIS Water Vapor Data. Since FY3A/MERSI has many similar characteristics with TERRA/MODIS, such as the passing time at equatorial descending node, the water vapor absorption channels, radiometric and spatial resolution, and their retrieval algorithm of water vapor also used the differential absorption method in the near-infrared channels, MODIS water vapor data are a good reference for validating the accuracy of MERSI water vapor product because the error of MODIS water vapor retrieved directly from the L1b images is $\pm 13 \%$ [12]. MODIS water vapor products (MOD05) are downloaded from the website (http://reverb.echo.nasa.gov/). And the dates of all MODIS water vapor data are corresponding to those of MERSI water vapor 5-minute product and summarized in Table 1.

2.3. Data of STRM DEM. The Shuttle Radar Topography Mission (STRM) is an international project spearheaded by NAG and NASA. SRTM was comprised of two specially modified radar systems, the C-band Spaceborne Imaging Radar and the X-band Synthetic Aperture Radar, which were flown on board the Space Shuttle Endeavour during the 11-day STS-99 mission on February 11-22, 2000 [28]. SRTM obtained the most complete and high-resolution digital elevation models (DEM) for approximately $80 \%$ of the world's land surface area from $56^{\circ} \mathrm{S}$ to $60^{\circ} \mathrm{N}$. The DEM data has a post spacing of 1 arc second (often quoted as 30- 


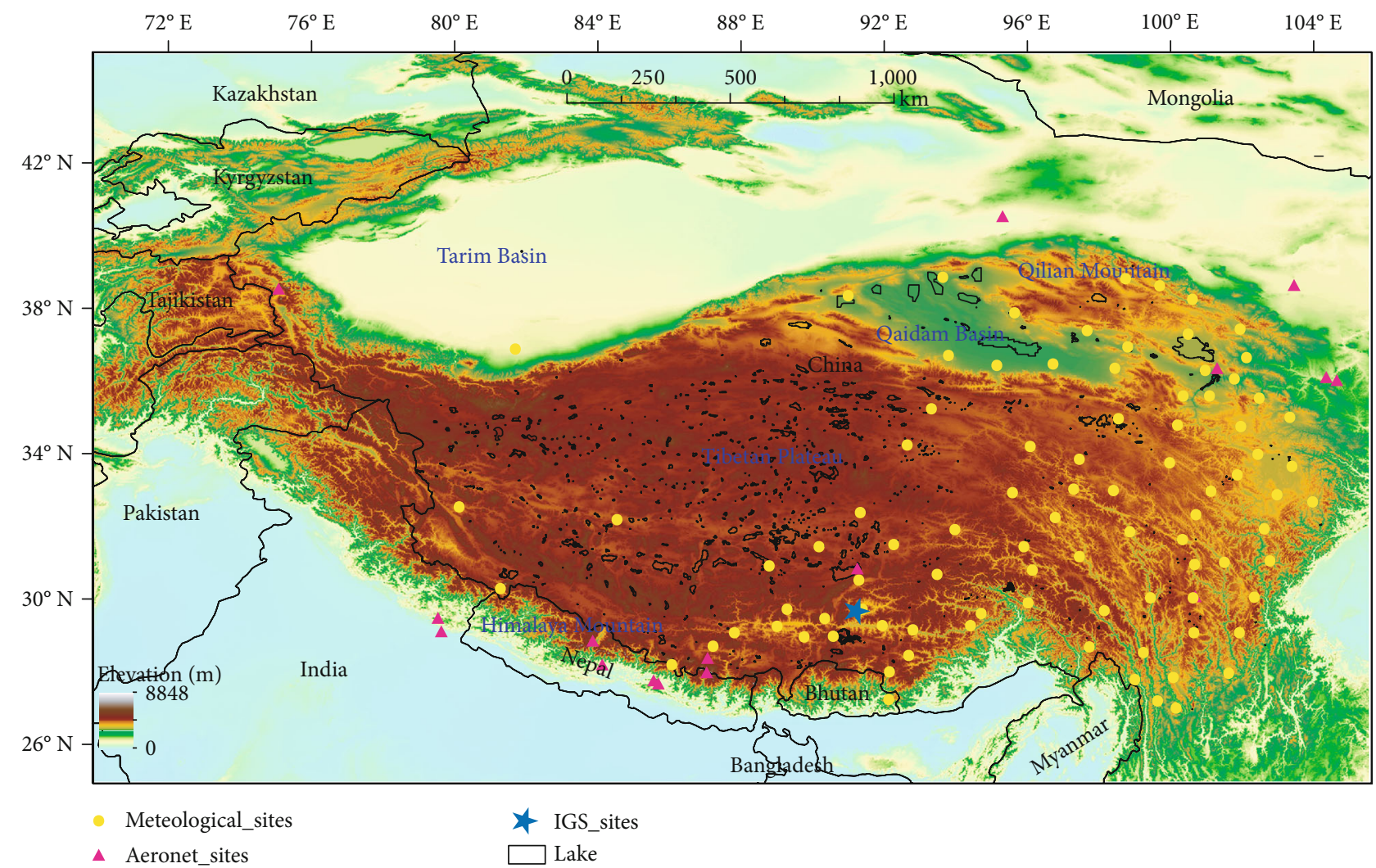

FIgURE 1: Distribution of referenced sites and the terrain in the Tibetan Plateau.

meter resolution) in the USA and a degraded 3 arc second (often quoted as 90-meter resolution) for the rest of the world with WGS84 geographic projection [29]. STRM DEM data for the Tibetan Plateau (Figure 1) were available on the CIAT-CSI SRTM website (http://srtm.csi.cgiar.org). For analyzing the influence of the terrain over the Tibetan Plateau on the distribution of water vapor, the slope and aspect was generated from DEM data by the Image Processing Software ENVI (Figure 2). All the data were resampled to $1 \mathrm{~km}$ resolution in order to match the MERSI water vapor products.

2.4. Preprocessing of MERSI Water Vapor Products. Since the MERSI 5-minute water vapor product includes the longitude and latitude data, the images of the product are firstly implemented geometrical correction using geographical coordinates with themselves. In order to compare MERSI water vapor product with the referenced water vapor data, the mean of the $3 \times 3$ neighborhood pixels corresponding to the centered location of referenced stations is calculated in the geometrically corrected MERSI PWV images. The matched time differences are controlled within 5 minutes, 15 minutes, and 30 minutes for ground-based GPS, Sun photometer, and Terra/MODIS, respectively.

As all the MERSI global monthly water vapor products are aggregated with a geographic coordinate system, here they only need to be registered. Taking MERSI monthly water vapor product in January, April, July, and October to stand for water vapor in winter, spring, summer, and autumn, respectively, all the monthly products in January,
April, July, and October from February 2010 to September 2015 are averaged to represent the water vapor in the four seasons in order to analyze the spatiotemporal variability of water vapor over the Tibetan Plateau. After the averaged MERSI water vapor images are cut by the vector boundary map of Tibetan Plateau, the four seasonal distribution maps of water vapor are drawn. Furthermore, when every image of MERSI monthly water vapor product is overlapped on the vector polygon of the Tibetan Plateau, the average of all the pixels within the polygon is calculated and regarded as the monthly water vapor value over the plateau, and the time series chart of water vapor over the Tibetan Plateau is drawn. All the preprocess procedures are quickly implemented through the batch programming codes in the ENVI/IDL environment [30].

\section{Results and Discussion}

3.1. Accuracy Analysis of MERSI PWV Product over the Tibetan Plateau. Since MERSI global daily, 10-day, and monthly water vapor products are aggregated by the 5minute one, and MERSI monthly water vapor products will be applied to analyze the spatiotemporal variation of water vapor over the Tibetan Plateau, the accuracy of MERSI 5minute water vapor products is firstly evaluated by three sources of water vapor data retrieved from the measurements of TERRA/MODIS, the ground-based GPS, and AERONET sun photometer. Due to the measured errors of GPS or sun photometer and incomplete removal cloud of MODIS or 


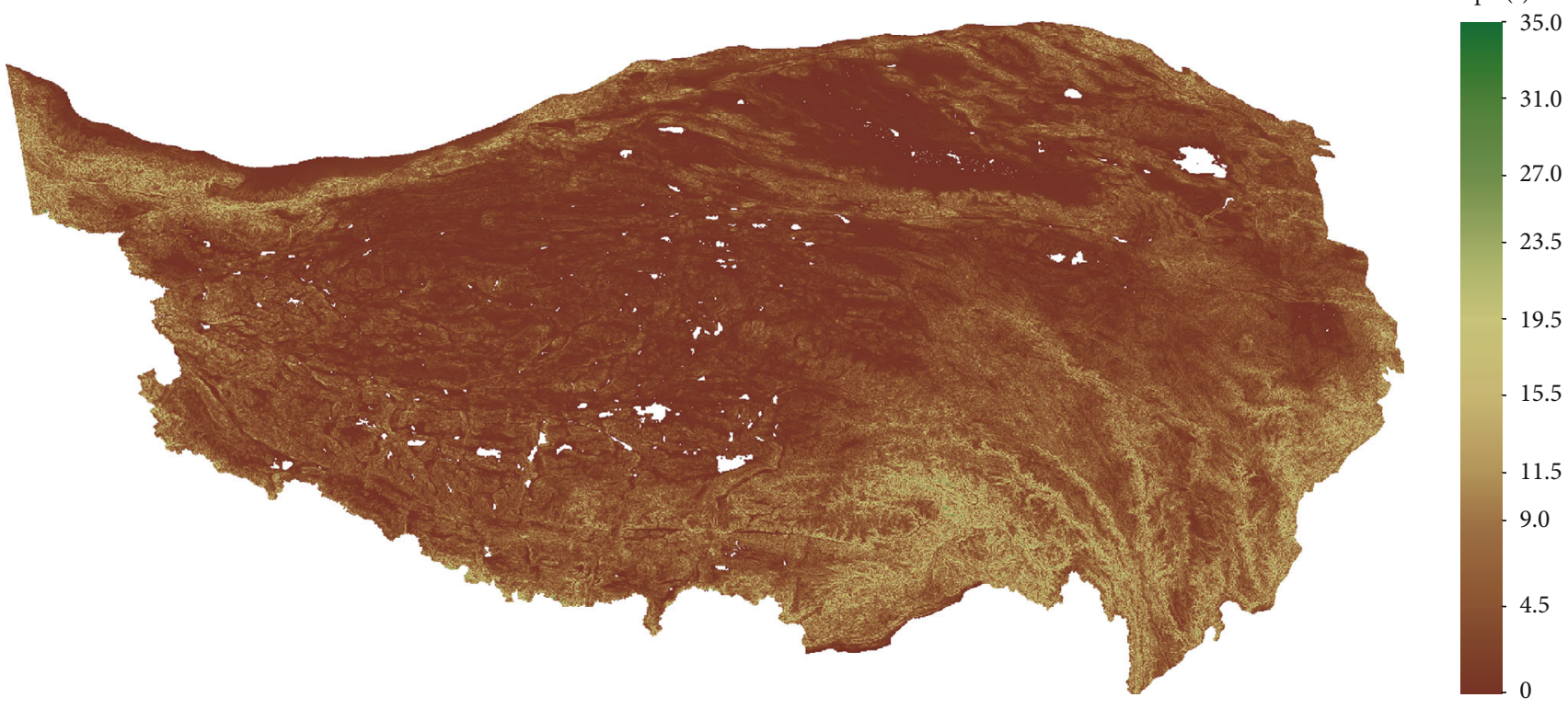

lope $\left(^{\circ}\right)$

(a)
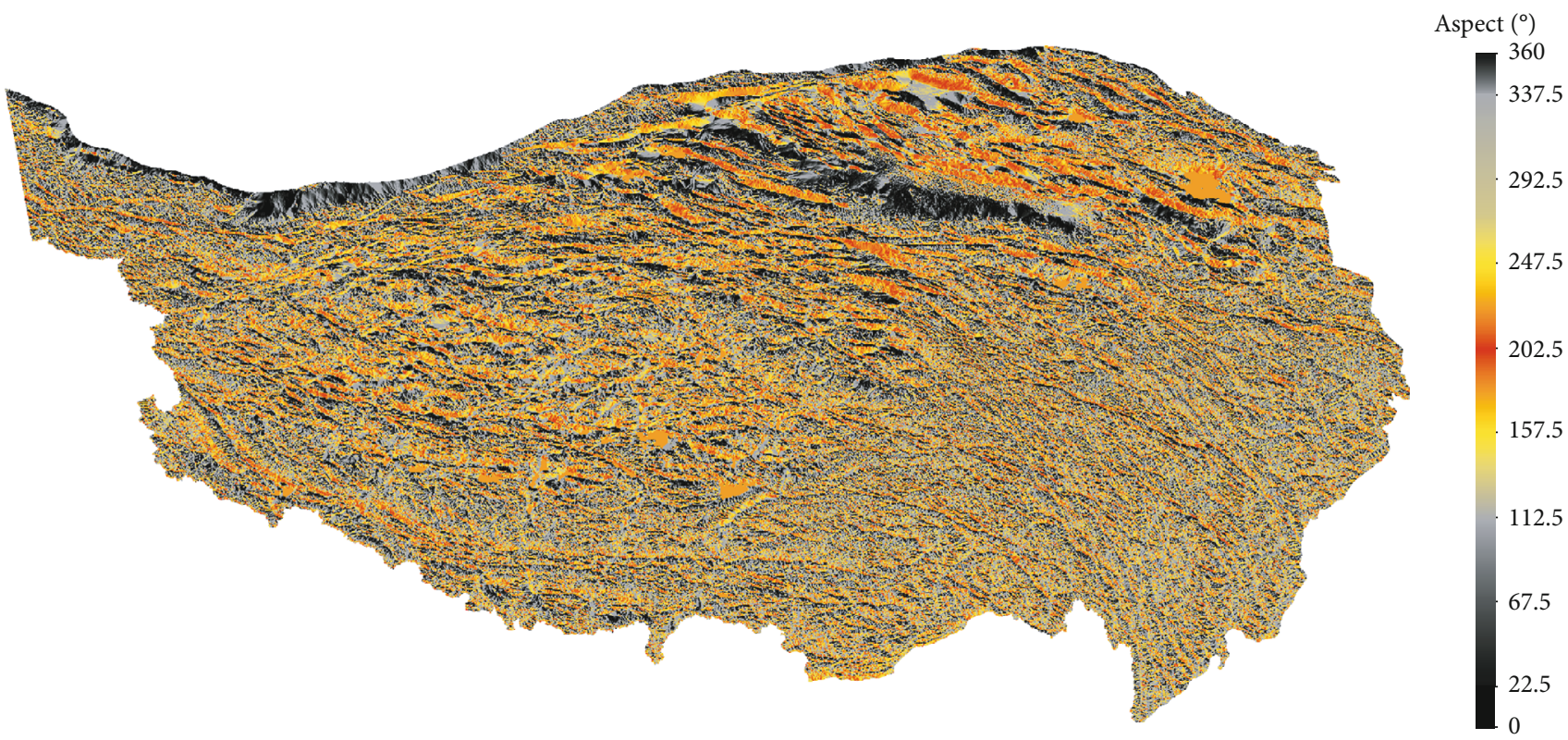

(b)

FIgURE 2: Slope and aspect of the Tibetan Plateau ((a) for slope and (b) for aspect).

MERSI raw images, there exists probably some outliers during the comparison. Therefore, the badly matched samples are removed automatically by a threshold value. When the outliers are eliminated from the matched samples, the scatter plots between the water vapor data of MERSI product and the reference are drawn, respectively, in Figure 3, and the evaluation indexes including Pearson's correlation coefficients $(R)$, mean bias (MB), root mean square error (RMSE), and mean absolute percentage error (MAPE) are selected to evaluate the accuracy of MERSI water vapor products.

Seen from Figure 3, although the number of the matched water vapor samples between MERSI 5-minute product and the three referenced data are different, the cor- relation coefficients still are within a high range of 0.905 to 0.925 , which are much higher than a threshold value 0.188 at a 99\% confidence level for the least 205 degrees of freedom and indicate the most significant correlation between MERSI 5-minute product and the three referenced data. Furthermore, most of matched data points are distributed near the $1: 1$ line in the scatter plots. This shows that MERSI 5-minute water vapor product agrees well with the referenced water vapor datasets.

Figure 3(a) is the water vapor scatter plot between GPS and MERSI; the number of samples is the least with 207 since there is only one available IGS station in the Tibetan Plateau, but $R$ is the highest with 0.925 , and the values of MAPE and 
0.918

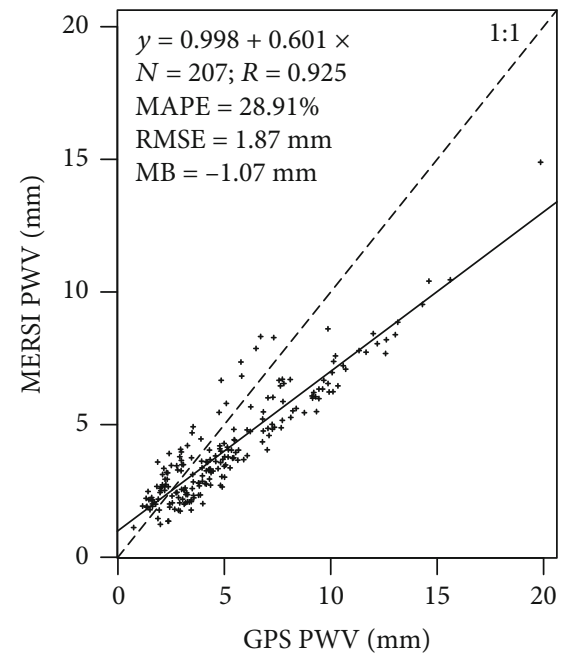

(a)

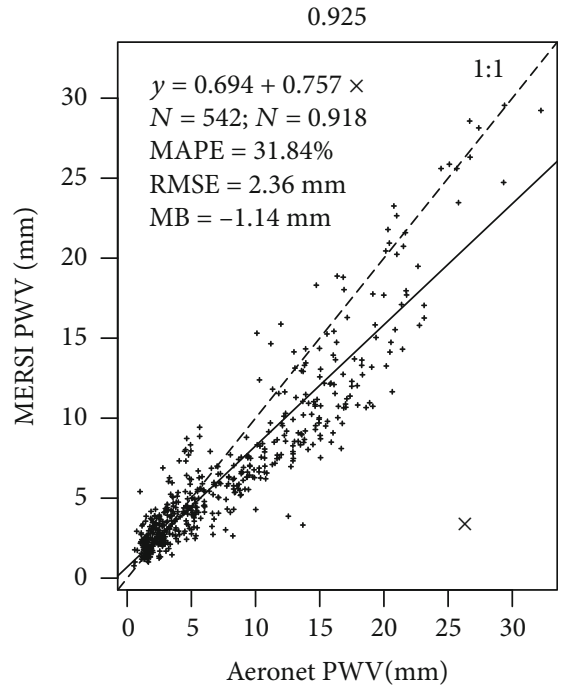

(b)

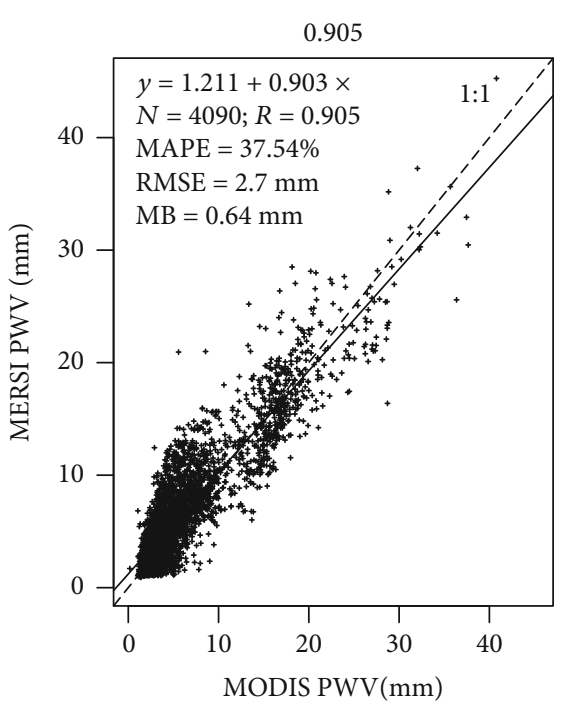

(c)

FIGURE 3: Comparison of water vapor values of MERSI with three referenced data ((a)-(c) represents the referenced data for GPS, AERONET, and MODIS, respectively).

RMSE are the smallest among the comparisons with three referenced data, that is, $28.91 \%$ and $1.87 \mathrm{~mm}$, respectively. Since the passing time of FY-3A satellite over the Tibetan Plateau is very close to the GPS receiver receiving time, and their time difference is within 5 minutes, the variability of PWV content in situ is very small. The low errors show that MERSI 5-minute water vapor product has a good accuracy in the Tibetan Plateau. The MB is negative, at $-1.07 \mathrm{~mm}$, which shows that MERSI 5-minute water vapor product is relatively lower than water vapor of ground-based GPS. Since the number of the matched samples is few and the water vapor content is very low over the IGS station, a small bias between MERSI water vapor product and the water vapor of groundbased GPS will result in a large difference between 1:1 line and the regression line. Hence, the intercept of 0.998 and slope of 0.601 are a little far from 0 and 1 , respectively. Figure $3(\mathrm{~b})$ is water vapor scatter plot between AERONET sun photometer and MERSI, the number of samples is 542 and $R$ is 0.918 , indicating that MERSI water vapor product is in good agreement with AERONET data. The MAPE, RMSE, and MB between MERSI water vapor product and AERONET water vapor are $31.84 \%, 2.36 \mathrm{~mm}$, and $-1.14 \mathrm{~mm}$, respectively, and the error values are in the middle among the comparisons with three reference data. The higher relative errors are due to two possible reasons except that the retrieval error of MERSI 5-minute water vapor product by itself. One is for the large uncertainty of AERONET water vapor data with $12 \%$, and the other is the long time difference within 15 minute neighborhood during FY-3A satellite passing and Sun photometer observing at AERONET stations. The MB is also below 0 , which shows that MERSI water vapor values are lower than the AERONET water vapor data. The intercept of 0.694 and slope of 0.757 are closer to 0 and 1, respectively; thus, the difference between the $1: 1$ line and the regression line is smaller than the comparison with the water vapor of ground-based GPS. Figure 3(c) is the water vapor scatter plot between MODIS and MERSI; the number of samples is the most with 4090 since the pixel values are derived from the two images by taking 91 meteorological stations in the Tibetan Plateau as the corresponding points. $R$ is 0.905 , showing MERSI water vapor values have a good correlation with those of MODIS. However, the errors here are the highest among the comparisons with three reference data, which the MAPE and RMSE are $37.54 \%$ and $2.76 \mathrm{~mm}$, respectively. The errors between MERSI and MODIS water vapor products are also due to the high uncertainty of MODIS water vapor product with $\pm 13 \%$ and the large overpass time difference of two satellites between FY-3A and TERRA about 30 minutes. Since most of matched water vapor samples are from the east of the Tibetan Plateau with relative higher water vapor values, and the number of samples is also the highest, the $\mathrm{MB}$ is very low with a positive value of $0.64 \mathrm{~mm}$, indicating that the MERSI water vapor values are a little higher than those of MODIS over the Tibetan Plateau. The regression line here is the closest to the $1: 1$ line and the slope of 0.903 is also approaching 1 despite the intercept of 1.211 being far from 0. Consequently, the MAPE of MERSI water vapor product is in the range of $28.91 \%-37.54 \%$, the RMSE ranges between 1.87 and $2.76 \mathrm{~mm}$, and the $\mathrm{MB}$ between -1.14 and $0.64 \mathrm{~mm}$ during the comparisons with the three referenced data, and MERSI water vapor product has the best agreement with GPS water vapor data, the second with AERONET water vapor data, then with MODIS water vapor product, which shows that MERSI water vapor product has good accuracy over the Tibetan Plateau.

3.2. Temporal and Spatial Analysis of Water Vapor in the Tibetan Plateau. Figure 4 shows the four seasonal distribution maps of water vapor over the Tibetan Plateau, which are drawn with the mean of MERSI monthly water vapor products from 2010 to 2015, where (a)-(d) represent winter, spring, summer, and autumn, respectively. Known from 


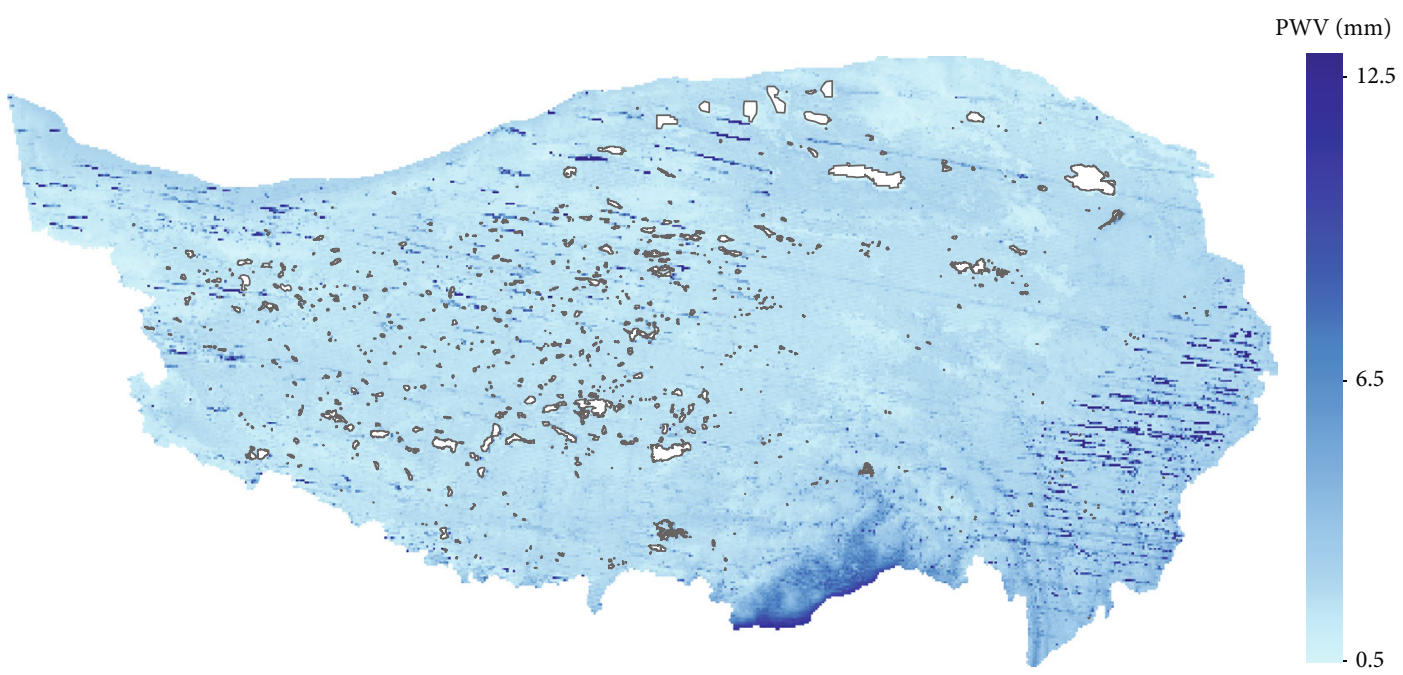

(a)

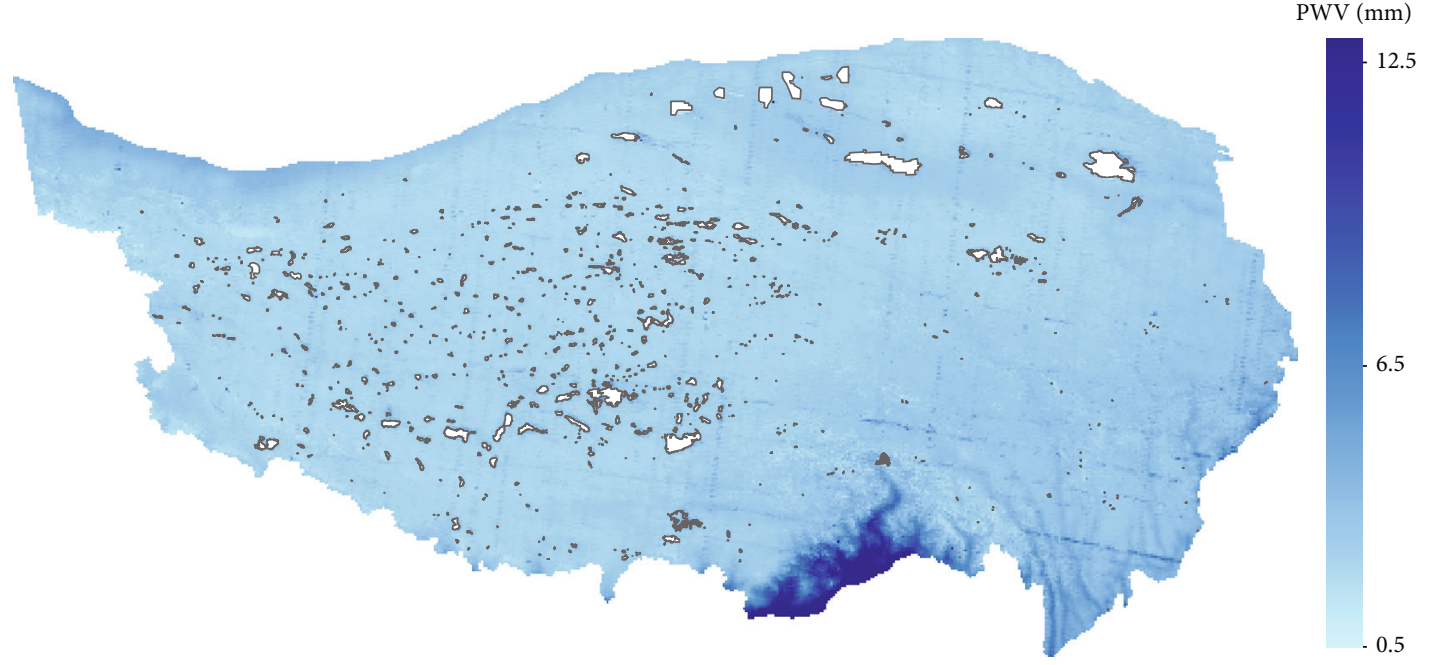

(b)

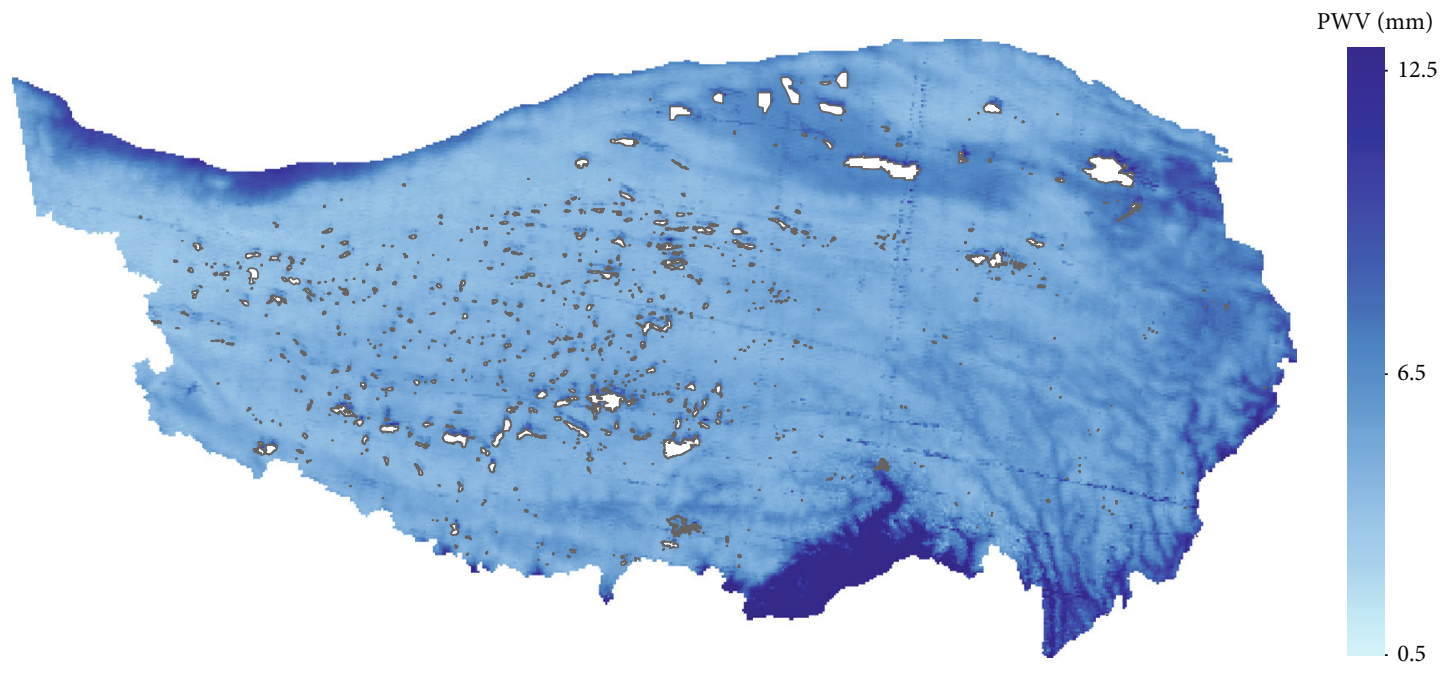

(c)

Figure 4: Continued. 


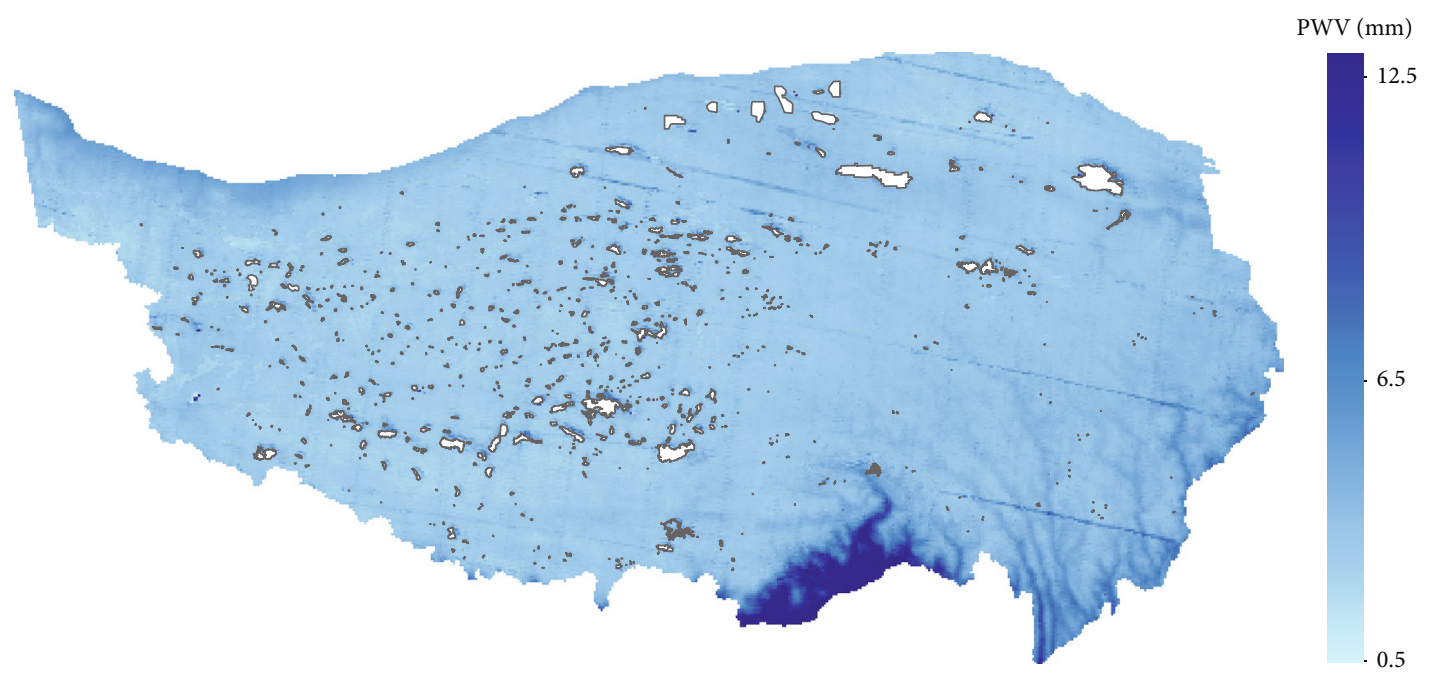

(d)

FIGURE 4: Seasonal distribution map of atmospheric water vapor over the Tibetan Plateau ((a)-(d) stands for winter, spring, summer, and autumn).

Figure 4, the spatial distribution of water vapor over the Tibetan Plateau displays the same pattern in the different seasons. There is the highest water vapor content for $12.50 \mathrm{~mm}$ in southern Tibet (called "Arunachal Pradesh" by India), where the elevation is low, appears to have both tropical and subtropical monsoon climates, and is affected by the Indian Ocean southwest monsoon, so there is the abundant moisture and heat due to enough rainfall and sunshine; therefore, it is warm and humid all year round $[4,5]$. The PWV content is higher for $11.93 \mathrm{~mm}$ in the east of the Tibetan Plateau and it gradually decreases from east to west. It is also found to be high for $6.55 \mathrm{~mm}$ in the northern part of the Qaidam Basin with relatively low elevation. Although the PWV content in the west of Tibetan Plateau is the lowest with $0.50 \mathrm{~mm}$, that in the northwest of Tibetan Plateau is relatively high with $9.47 \mathrm{~mm}$, which lies in the southern margin of the Tarim Basin with the lower elevation. The spatial distribution of water vapor over the Tibetan Plateau is mainly related to elevation. The higher the elevation is, the shorter the column of atmospheric water vapor is. Research shows that $70-75 \%$ of the PWV content is located in the atmospheric layer from surface to $700 \mathrm{hPa}$ in the low elevation area, while the PWV content is close to 0 in the surface $-700 \mathrm{hPa}$ layer in the areas above $3000 \mathrm{~m}$ where the surface atmospheric pressure is less than $700 \mathrm{hPa}$. Over the plateau, the $700-400 \mathrm{hPa}$ layer contains $80-90 \%$ of the water vapor and the $400-200 \mathrm{hPa}$ layer contains $10-20 \%$ [10]. As the geopotential height increases, the water vapor content in the atmospheric column will reduce, so the integrated water vapor content is low in the areas with high elevation.

In order to analyze the seasonal distribution of water vapor over the Tibetan Plateau, the lake areas of the different sizes in the Tibetan Plateau have been masked. The water vapor over the Tibetan Plateau displays the distinct seasonal characteristics. The PWV content in winter is the lowest at 0.57-6.60 mm over the whole plateau. Spring and autumn is the transitional season between winter and summer, and the PWV content in the spring is the second lowest, with $1.20-6.80 \mathrm{~mm}$. That in summer is the highest and it is 2.40 $12.50 \mathrm{~mm}$ while that in autumn is the second highest for $1.55-10.00 \mathrm{~mm}$. The seasonal variability of water vapor over the Tibetan Plateau is mainly due to the influence of the Asian monsoon circulation on water vapor transportation [31]. In winter, less water vapor is transported into the Tibetan Plateau and it is very dry since the influence of westerlies is weak, the current is blocked by the western terrain of Pamir Plateau, and water vapor is reduced from the northern Arabian Sea. In addition, the air temperature is also low in the Tibetan Plateau, the land surface is covered with much snow and ice, and the surface evaporation gets less. The transportation of water vapor in the plateau is enhanced gradually during spring. The water vapor from the Yarlung Zangbo Grand Canyon and the Tarim Basin, even from the Pamirs moves into the Tibetan Plateau region and the PWV content increases gradually. With the summer monsoon prevailing in Asia, water vapor from the South China Sea is transported westward and merges with water vapor from the Arabian Sea and the Bay of Bengal; hence, the Tibetan Plateau becomes a transfer station of water vapor over the continent, then the water vapor is transported continually to the east and north of China. Furthermore, since the plateau in summer is a main heat source where the thunderstorm and convection takes place frequently and atmospheric water vapor is majorly transported in the vertical. The snow is evaporated fast in mountains and the plant transpiration is increased, indicating the flood season with more rains in summer, these reasons will result in increasing the water vapor content over Tibetan Plateau. In autumn, the transportation of water vapor from the Arabian Sea to the Tibetan Plateau decreases and the PWV content in the plateau gets less [31].

In order to discover further the interannual variability of water vapor over the Tibetan Plateau, the time series chart of the monthly average water vapor content over the whole 


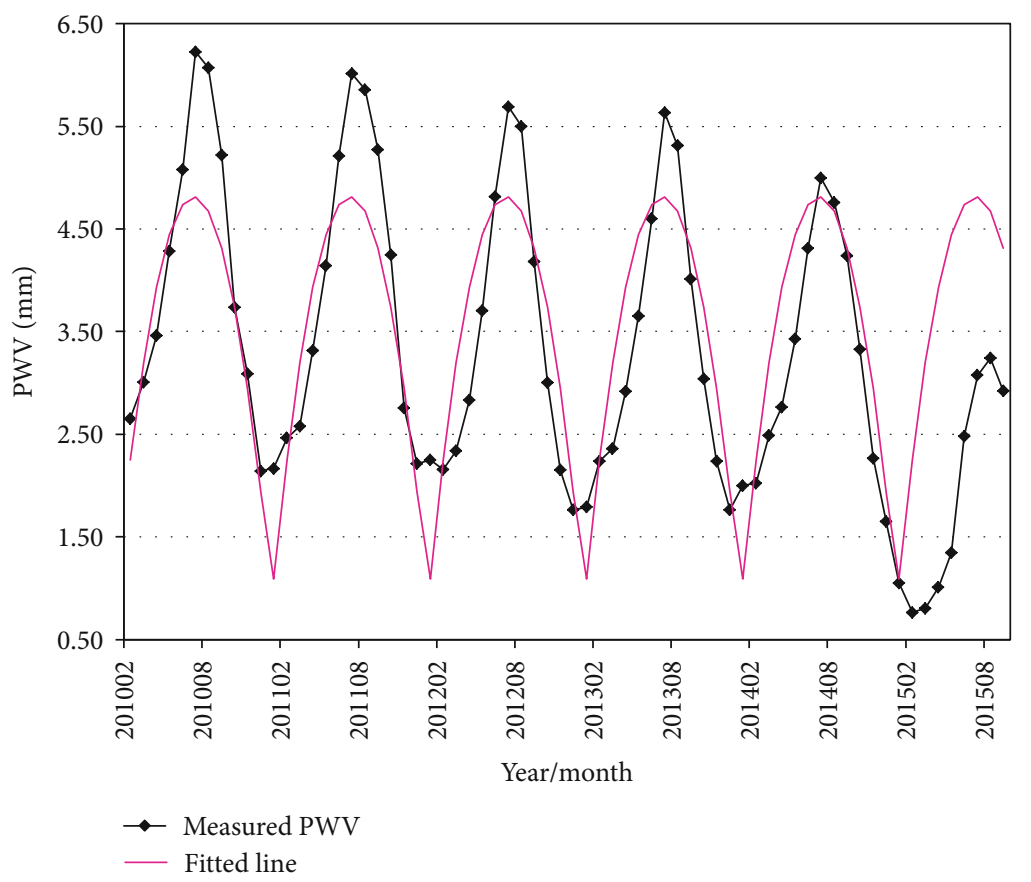

Figure 5: Time series chart of average water vapor content in the Tibetan Plateau.

plateau was made based on MERSI monthly water vapor product (Figure 5). Known from Figure 5, the water vapor over the Tibetan Plateau shows an annual periodic variation; the water vapor content is the lowest about $2.00 \mathrm{~mm}$ in December, and then increases monthly till it peaks with $6.00 \mathrm{~mm}$ in July and then decreases gradually. The relationship of annual water vapor content with month tends to a quadratic polynomial law. In this study, the average water vapor content over the Tibetan Plateau during February 2010 to December 2014 is fitted to a quadratic polynomial function, and the regression model is obtained as PWV $=-0.2951+1.4916 \mathrm{t}-0.1088 t^{2}$, where $t$ is month, the number of samples for the model is 59 , the coefficient of determination $R^{2}$ is 0.734 , and the RMSE is $0.695 \mathrm{~mm}$. The model reaches 99\% significant level checked with $F$ -test method. The values of statistical parameters $R^{2}$ and RMSE show that the fitted model has a good predicted accuracy. When the fitted regression line is added in the chart, it is found that the fitted maximum and minimum water vapor values during a year are always lower than the MERSI PWV ones, but the MERSI PWV values in other months are very close to the predicted ones, which illuminates that the quadratic polynomial function is able to reflect approximately the monthly variation tendency of water vapor over the Tibetan Plateau. It should be noted that the MERSI monthly water vapor product shows a decreasing tendency with time as seen in Figure 5; this is possibly due to the degeneration of sensor, because the values of MERSI monthly water vapor product are much lower after February 2015 and FY-3A/MERSI does not work after 10 March 2018.

3.3. Impact of Topographic Factors on Water Vapor. The research showed that topographic factors could affect the spatial distribution of atmospheric water vapor [10]. There is very high elevation and complex terrain in the Tibetan Plateau. In order to analyze the influence of topographic factors on the distribution of water vapor, MERSI monthly water vapor product is carried out the correlation analysis with the elevation, slope, aspect, latitude and longitude in the Tibetan Plateau, respectively. Firstly, the topographic factors, including elevation, slope, and aspect are resized to a $5 \mathrm{~km}$ resolution to match the MERSI monthly water vapor product, and the number of all the pixels within the image of MERSI and topographic factors is 2524677 . Then, the correlation analysis is carried out for all the pixels between MERSI monthly water vapor product from February 2010 to September 2015 and each topographic factor (included the longitude and latitude at each pixel), respectively. Finally, the time series chart (Figure 6) of the correlation coefficient between topographic factors and water vapor is shown. As can be seen from Figure 6, the elevation and latitude are negatively correlated with water vapor, which indicates that the water vapor content gradually decreases with increasing elevation and latitude. The correlation between the elevation and water vapor is the best, $R$ is between -0.258 and -0.725 , and displays a certain seasonal variation. The best relationship appears in summer with an $R$ of -0.725 and the worst one in winter with $R$ of -0.258 . This is mainly due to two possible reasons: the higher the elevation is, the shorter atmospheric water vapor vertical column is, thus the lower the PWV content would be; the difference of air temperature in different seasons results in the distinct evaporation of water vapor over the surface. Since the air temperature is high in summer, the water vapor near surface evaporates quickly; hence, the PWV in the short atmospheric column in the area of high elevation varies considerably. The latitude of the Tibetan Plateau is between 25 and $40^{\circ} \mathrm{N}$ and the correlation coefficient ranges from -0.110 to -0.391 with water vapor 


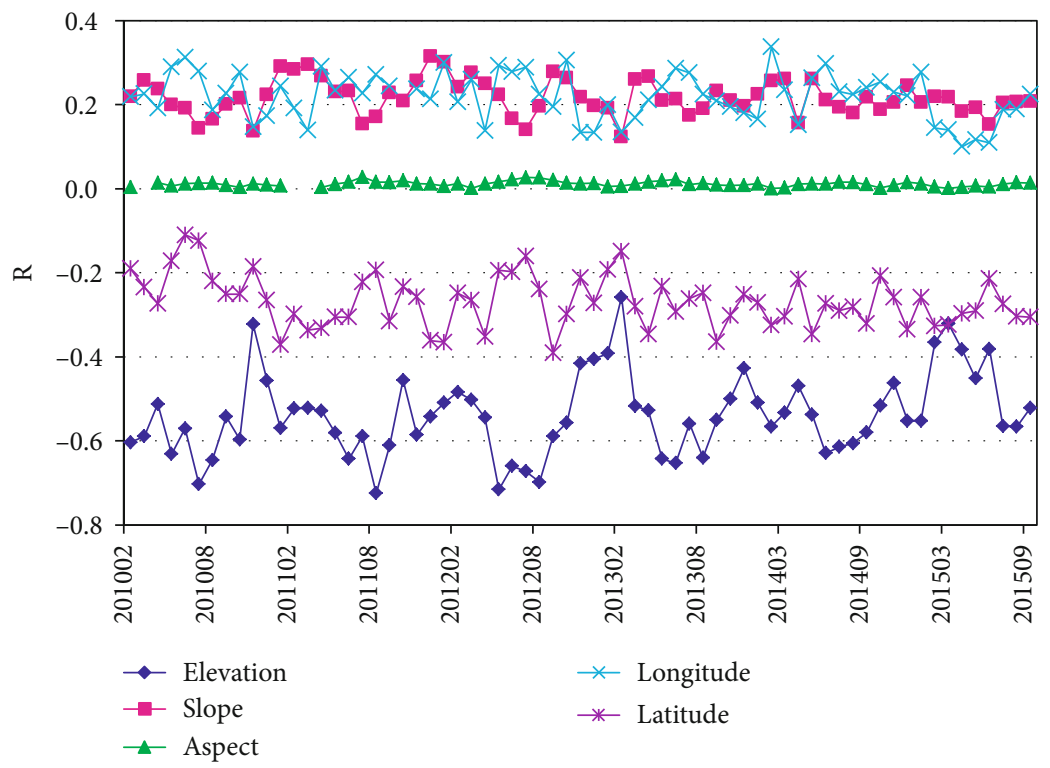

Figure 6: Time series chart of correlation coefficient between topographic factors and water vapor in the Tibetan Plateau.

content. Since the number of samples is 2524677 for all the pixels in the whole image, the minimum $R$ is faithfully obtained at $99 \%$ significant level checked with correlation test. The solar incident angle and duration of sunshine always vary with changing latitudes. The higher the latitude is, the shorter the duration of sunshine is. When the land surface receives smaller amount of solar radiation, the water vapor in the surface will be evaporated less. In the south of the Tibetan Plateau, the atmospheric water vapor content is very high, where is situated in low latitude with rich moisture and heat. Bannon et al. [32] also confirmed that water vapor in the northern hemisphere decreased with increasing latitudes from the equator to the North Pole. There is a positive correlation between the slope, longitude, and water vapor in the Tibetan Plateau. The correlation coefficients are between 0.124-0.315 and 0.100-0.337, respectively, and they also reach a $99 \%$ significant level due to the large number of samples, but the seasonal variation of the correlation coefficient is not obvious. The slope in the Tibetan Plateau is mainly between 0 and $35^{\circ}$ (Figure 2(a)). As the slope increases, the incident angle between the sunshine and the ground enlarges, and the solar radiative effective area increases, then the ground surface is able to receive more solar radiation, so water vapor in the surface is evaporated quickly, which results in the increase of atmospheric water vapor content. The longitude of the Tibetan Plateau stretches across from 70 to $105^{\circ} \mathrm{E}$, which has a significant positive correlation with the atmospheric water vapor. Along the longitude from west to east, there is transportation of the water vapor from the Yellow Sea and the East China Sea in the east of China, thus, a gradual increase in the water vapor. The aspect of the Tibetan Plateau varies between 0 and $360^{\circ}$ (Figure 2(b)) and the aspect of $0-22.5^{\circ}$ or $337.5-360^{\circ}$ is defined as ubac, $22.5-112.5^{\circ}$ or $247.5-337.5^{\circ}$ as semiubac, $112.5-157.5^{\circ}$ or $202.5-247.5^{\circ}$ as semiadret, and $157.5-202.5^{\circ}$ as adret [33]. The aspect can also influence the distribution of solar radiation in the ground surface. Seen from the Figure 2(b), the ubac and adret areas are not significantly distinct, and the correlation coefficient between aspect and water vapor in the whole Plateau is very low around 0.01 , which shows that the aspect has the weak effect on the water vapor over the Tibetan Plateau.

\section{Conclusion}

Based on the validation of MERSI 5-minute water vapor product over the Tibetan Plateau, this paper analyzes the spatiotemporal distribution characteristic of water vapor and discusses the effects of terrain on water vapor over the Tibetan Plateau. The following results were obtained:

(1) Compared with the water vapor data from MODIS, ground-based GPS, and AERONET sun photometer, the MAPE of FY-3A/MERSI water vapor product is in the range of $28.91 \%-37.54 \%$, the RMSE ranging from 1.87 to $2.76 \mathrm{~mm}$, and the $\mathrm{MB}$ between -1.14 and $0.64 \mathrm{~mm}$; MERSI water vapor product displays the best agreement with GPS water vapor data, second with AERONET water vapor data, then with MODIS water vapor product, which shows that MERSI water vapor product has a good accuracy over the Tibetan Plateau

(2) The distribution of water vapor over the Tibetan Plateau displays a certain spatial pattern, that is, the water vapor content is highest in southern Tibet, followed by the eastern, and then PWV content gradually decreases with the increase of elevation from the east to the west. That is, it is high in the northern Qaidam Basin and the southern margin of the Tarim Basin with low elevation. The seasonal variation of water vapor over the Tibetan Plateau is obvious. The PWV content is lowest in winter for 0.57$6.60 \mathrm{~mm}$. Spring and autumn are the transitional 
seasons of winter and summer, with spring having $1.20-6.80 \mathrm{~mm}$, while the PWV content in autumn has high values of $1.55-10.00 \mathrm{~mm}$, and that in summer is the highest for $2.40-12.50 \mathrm{~mm}$. The annual water vapor over the Tibetan Plateau presents a periodic variation and accords with the quadratic polynomial law

(3) The topographic factors of the Tibetan Plateau have a certain impact on the water vapor. The elevation and latitude were negatively correlated with water vapor, indicating that the PWV content is decreased with elevation and increasing with latitude. The slope and longitude are positively correlated with water vapor, while the aspect does not have a significant effect on water vapor

\section{Data Availability}

All the MERSI water vapor products used in this study were available in the FengYun satellite remote sensing data service network (http://satellite.cma.gov.cn/portalsite/default.aspx). The troposphere zenith path delay (ZPD) and relative meteorological data were obtained from the Scripps Orbit and Permanent Array Center (ftp://cddis.gsfc.nasa.gov/). The level 2.0 data of AERONET were derived from the website (http://aeronet.gsfc.nasa.gov/). The MODIS water vapor products (MOD05) were downloaded from the Earth Observing System Data and Information System (http:// reverb.echo.nasa.gov/). And the STRM DEM data were taken from the CIAT-CSI SRTM website (http://srtm.csi.cgiar.org).

\section{Conflicts of Interest}

The authors declare that they have no conflicts of interest.

\section{Acknowledgments}

This research was funded jointly by the Project of Humanities and Social Sciences of the Ministry of Education in China (grant number:16YJCZH021), the construction project of weather modification in the Northwest China from China Meteorological Administration (grant number: RYSY201907), and the research fund of NUIST-UoR International Research Institute (grant number: 1321041901001).The authors thank the FengYun satellite remote sensing data service network, AErosol RObotic NETwork (AERONET), Earth Observing System Data and Information System (EOSDIS), Scripps Orbit and Permanent Array Center (UCSD), and the Shuttle Radar Topography Mission for their data support.

\section{References}

[1] S. Zhou, P. Wu, C. Wang, and J. Han, "Spatial distribution of atmospheric water vapor and its relationship with precipitation in summer over the Tibetan Plateau," Journal of Geographical Sciences, vol. 22, no. 5, pp. 795-809, 2012.

[2] B. C. Gao, P. Yang, G. Guo, S. K. Park, W. J. Wiscombe, and B. Chen, "Measurements of water vapor and high clouds over the Tibetan Plateau with the Terra MODIS instrument," IEEE
Transactions on Geoscience and Remote Sensing, vol. 41, pp. 895-900, 2003.

[3] X. Xu, "The effects of sensitive region over Tibetan Plateau on disastrous weather and climate and its monitoring," Engineering Sciences, vol. 11, pp. 96-107, 2009.

[4] X. Liu and B. Chen, "Climatic warming in the Tibetan Plateau during recent decades," International Journal of Climatology: A Journal of the Royal Meteorological Society, vol. 20, no. 14, pp. 1729-1742, 2000.

[5] Y. Zhang, D. Wang, P. Zhai, G. Gu, and J. He, "Spatial distributions and seasonal variations of tropospheric water vapor content over the Tibetan Plateau," Journal of Climate, vol. 26, no. 15, pp. 5637-5654, 2013.

[6] R. D. Cess, G. L. Potter, J. P. Blanchet et al., "Intercomparison and interpretation of climate feedback processes in 19 atmospheric general circulation models," Journal of Geophysical Research, vol. 95, no. D10, pp. 16601-16615, 1990.

[7] M. Bevis, S. Businger, T. A. Herring, C. Rocken, R. A. Anthes, and R. H. Ware, "GPS meteorology: Remote sensing of atmospheric water vapor using the global positioning system," Journal of Geophysical Research, vol. 97, no. D14, pp. 15787-15801, 1992.

[8] R. N. Halthore, T. F. Eck, B. N. Holben, and B. L. Markham, "Sun photometric measurements of atmospheric water vapor column abundance in the 940-nm band," Journal of Geophysical Research, vol. 102, no. D4, pp. 4343-4352, 1997.

[9] P. K. Karmakar, M. Maiti, S. Sett, C. F. Angelis, and L. A. T. Machado, "Radiometric estimation of water vapor content over Brazil," Advances in Space Research, vol. 48, no. 9, pp. 1506-1514, 2011.

[10] P. Zhai and R. Eskridge, "Atmospheric water vapor over China," Journal of Climate, vol. 10, no. 10, pp. 2643-2652, 1997.

[11] R. Kistler, E. Kalnay, W. Collins et al., “The NCEP-NCAR 50year reanalysis: monthly means CD-ROM and documentation," Bulletin of the American Meteorological Society, vol. 82, no. 2, pp. 247-267, 2001.

[12] Y. Kaufman and B. Gao, "Remote sensing of water vapor in the near IR from EOS/MODIS," IEEE Transactions on Geoscience and Remote Sensing, vol. 30, no. 5, pp. 871-884, 1992.

[13] B. C. Gao and Y. J. Kaufman, "Water vapor retrievals using Moderate Resolution Imaging Spectroradiometer (MODIS) near-infrared channels," Journal of Geophysical Research, vol. 108, pp. 4389-4398, 2003.

[14] H. Liu, S. Tang, S. Zhang, and J. Hu, "Evaluation of MODIS water vapour products over China using radiosonde data," International Journal of Remote Sensing, vol. 36, no. 2, pp. 680-690, 2015.

[15] H. Liu, S. Tang, J. Hu, S. Zhang, and X. Deng, "An improved physical split-window algorithm for precipitable water vapor retrieval exploiting the water vapor channel observations," Remote Sensing of Environment, vol. 194, pp. 366-378, 2017.

[16] J. Liu, H. Liang, Z. Sun, and X. Zhou, "Validation of the Moderate-Resolution Imaging Spectroradiometer precipitable water vapor product using measurements from GPS on the Tibetan Plateau," Journal of Geophysical Research, vol. 111, no. D14, 2006.

[17] L. Sun, X. Hu, M. Guo, and N. Xu, "Multisite calibration tracking for FY-3A MERSI solar bands," IEEE Transactions on Geoscience and Remote Sensing, vol. 50, no. 12, pp. 4929-4942, 2012. 
[18] X. Hu, Y. Huang, Q. Lu, and J. Zheng, "Retrieving precipitable water vapor based on the near-infrared data of FY-3A satellite," Journal of Applied Meteorological Science, vol. 22, pp. 46-56, 2011.

[19] B. N. Holben, T. F. Eck, I. Slutsker et al., “AERONET-A Federated Instrument Network and Data Archive for Aerosol Characterization," Remote Sensing of Environment, vol. 66, no. 1, pp. 1-16, 1998.

[20] J. Duan, M. Bevis, P. Fang et al., "GPS meteorology: direct estimation of the absolute value of precipitable water," Journal of Applied Meteorology, vol. 35, pp. 830-838, 1998.

[21] P. Tregoning, R. Boers, D. O'Brien, and M. Hendy, “Accuracy of absolute precipitable water vapor estimates from GPS observations," Journal of Geophysical Research, vol. 103, no. D22, pp. 28701-28710, 1998.

[22] X. Li, G. Dick, C. Lu et al., "Multi-GNSS meteorology: realtime retrieving of atmospheric water vapor from BeiDou, Galileo, GLONASS, and GPS observations," IEEE Transactions on Geoscience and Remote Sensing, vol. 53, no. 12, pp. 6385-6393, 2015.

[23] C. Lu, X. Li, T. Nilsson et al., "Real-time retrieval of precipitable water vapor from GPS and BeiDou observations," Journal of Geodesy, vol. 89, no. 9, pp. 843-856, 2015.

[24] S. H. Byun and Y. E. Bar-Sever, "A new type of troposphere zenith path delay product of the international GNSS service," Journal of Geodesy, vol. 83, pp. 367-373, 2009.

[25] G. Elgered, J. L. Davis, T. A. Herring, and I. I. Shapiro, "Geodesy by radio interferometry: Water vapor radiometry for estimation of the wet delay," Journal of Geophysical Research, vol. 96, no. B4, pp. 6541-6555, 1991.

[26] N. Lu, J. Qin, K. Yang, Y. Gao, X. Xu, and T. Koike, “On the use of GPS measurements for Moderate Resolution Imaging Spectrometer precipitable water vapor evaluation over southern Tibet," Journal of Geophysical Research, vol. 116, no. D23, 2011.

[27] I. Sano, S. Mukai, M. Yamano, T. Takamura, T. Nakajima, and B. Holben, "Calibration and validation of retrieved aerosol properties based on AERONET and SKYNET," Advances in Space Research, vol. 32, no. 11, pp. 2159-2164, 2003.

[28] A. Jarvis, H. I. Reuter, and A. E. Nelson, "Hole-filled seamless SRTM data V4, International Centre for Tropical Agriculture (CIAT)," 2008, available: http://srtm.csi.cgiar.org.

[29] H. Reuter, A. Nelson, and A. Jarvis, "An evaluation of void filling interpolation methods for SRTM data," International Journal of Geographical Information Science, vol. 21, no. 9, pp. 983-1008, 2007.

[30] S. Gong, D. F. T. Hagan, X. Wu, and G. Wang, "Spatio-temporal analysis of precipitable water vapour over Northwest China utilizing MERSI/FY-3A products," International Journal of Remote Sensing, vol. 39, no. 10, pp. 3094-3110, 2018.

[31] H. Liang, J. Liu, and S. Li, "Analysis of precipitable water vapor source distribution and its seasonal variation characteristics over Tibetan Plateau and its surroundings," Journal of Natural Resources, vol. 21, pp. 526-535, 2006.

[32] J. K. Bannon and L. P. Steele, Average water vapour content of the air, Geophys. Mem., 102, British Meteorological Office, London, 1960.

[33] Z. Yu, C. Zhang, J. Chen, and C. He, “Topographic correction of sunny and shady slope in different division methods based on slope-matching model," Journal of Southwest Forestry University, vol. 37, pp. 178-187, 2017. 


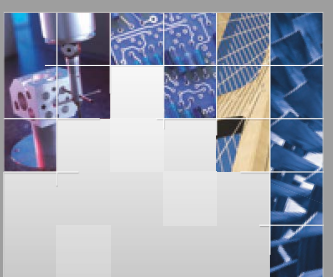

\section{Enfincering}
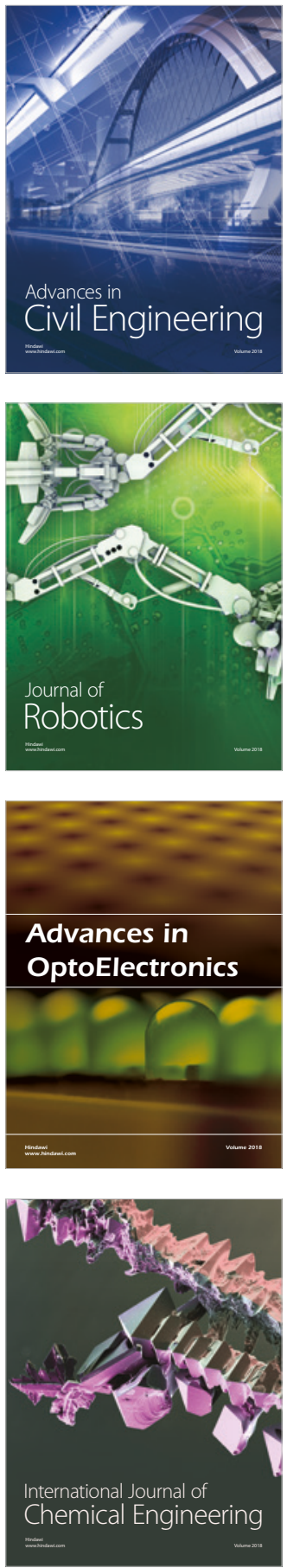

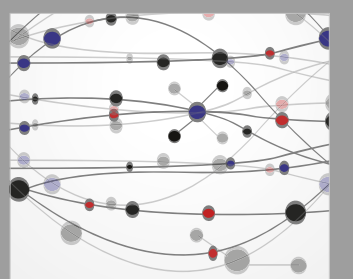

\section{Rotating \\ Machinery}

The Scientific World Journal

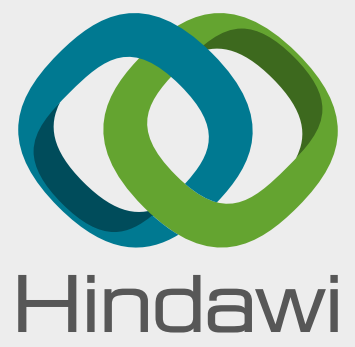

Submit your manuscripts at

www.hindawi.com
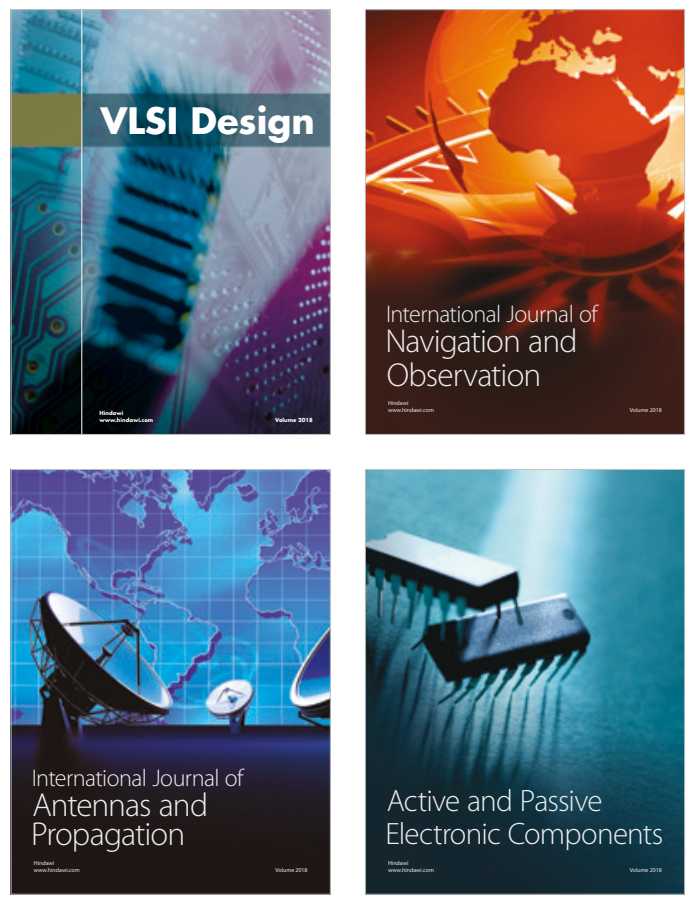
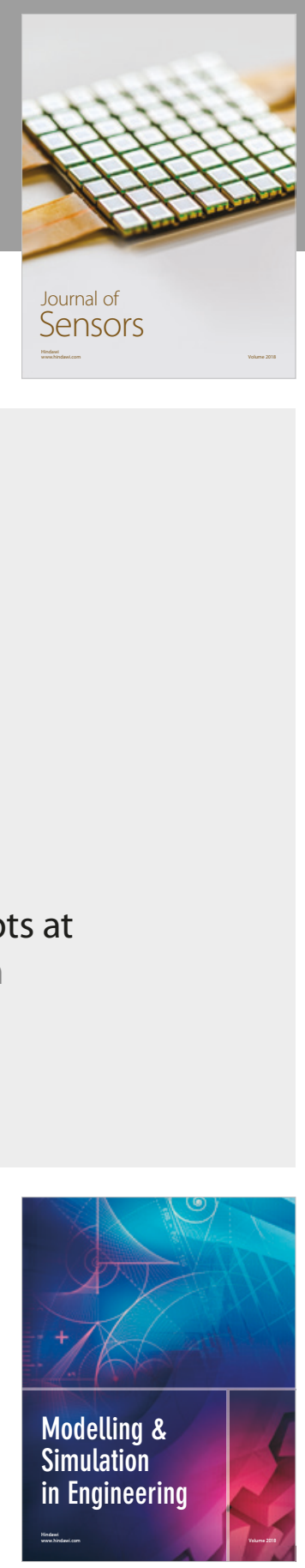

\section{Advances \\ Multimedia}
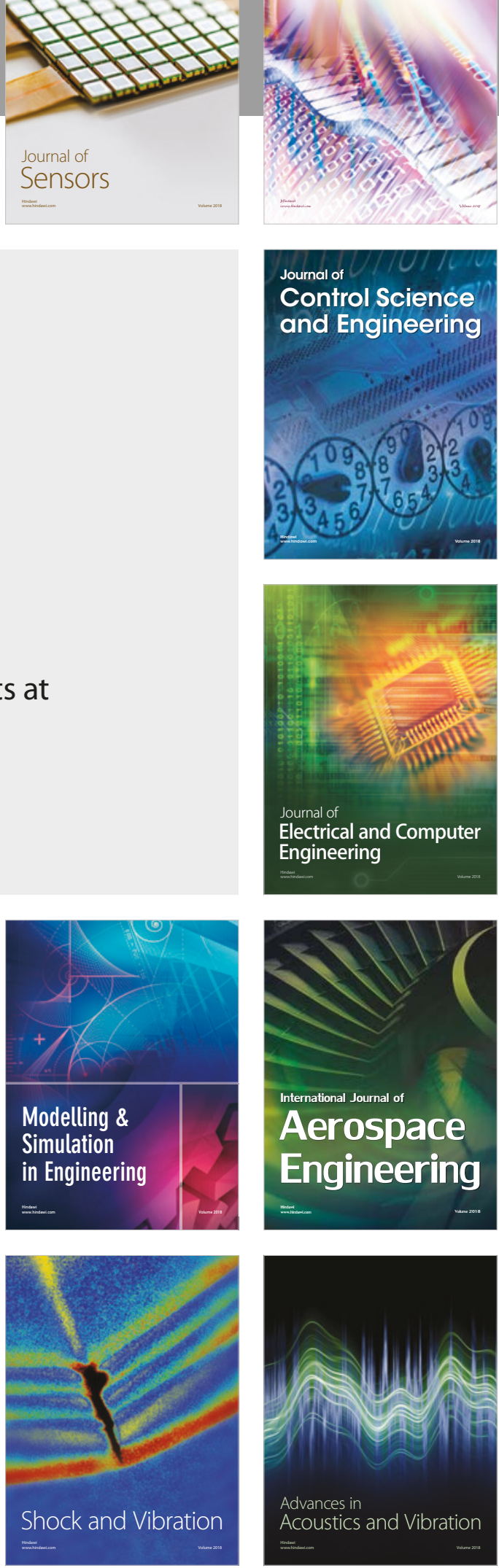